Article

\title{
Applications of Lactobacillus rhamnosus Spent Culture Supernatant in Cosmetic Antioxidation, Whitening and Moisture Retention Applications
}

\author{
Cheng-Chih Tsai ${ }^{1}$, Chin-Feng Chan ${ }^{2}$, Wen-Ying Huang ${ }^{2}$, Jin-Seng Lin ${ }^{2}$, Patty Chan ${ }^{2}$, \\ Ho-Yen Liu ${ }^{2}$ and Yung-Sheng Lin ${ }^{2, *}$
}

1 Department of Food Science and Technology, Hungkuang University, Taichung 43302, Taiwan; E-Mail: tsaicc@sunrise.hk.edu.tw

2 Department of Applied Cosmetology and Master Program of Cosmetic Science, Hungkuang University, Taichung 43302, Taiwan; E-Mails: cfchan@sunrise.hk.edu.tw (C.-F.C.); beca690420@hk.edu.tw (W.-Y.H.); jinsenglin@gmail.com (J.-S.L.); ving127@gmail.com (P.C.); wenyenliu@yahoo.com.tw (H.-Y.L.)

* Author to whom correspondence should be addressed; E-Mail: linys@sunrise.hk.edu.tw; Tel.: +886-4-2631-8652 (ext. 3684); Fax: +886-4-2632-1046.

Received: 16 October 2013; in revised form: 12 November 2013 / Accepted: 13 November 2013 / Published: 15 November 2013

\begin{abstract}
This study was aimed at investigating the antioxidant, whitening, and moisture-retention properties of Lactobacillus rhamnosus spent culture supernatant (Lr-SCS) in cosmetic applications. Results reveal that Lr-SCS effectively and gradually scavenges 1,1-diphenyl-2-picrylhydrazyl as well as 2,2-azino-bis-(3-ethylbenzothiazoline-6-sulfonic acid) radical cations, and increases reducing power in a dose-dependent manner. Additionally, Lr-SCS can also suppress tyrosinase activity in vitro and effectively promote moisture retention. Heat treatment at $100{ }^{\circ} \mathrm{C}$ for $30 \mathrm{~min}$ does not influence the functions of Lr-SCS. We conclude that Lr-SCS can be used effectively in skin care cosmetics.
\end{abstract}

Keywords: Lactobacillus rhamnosus; antioxidation; whitening; moisture retention; tyrosinase

\section{Introduction}

The World Health Organization defines probiotics as live microorganisms conferring a health benefit on the host when administered in adequate amounts. Probiotic bacterial cultures modulate the 
growth of intestinal microbiota, potentially suppressing harmful bacteria and reinforcing the body's natural defense mechanisms. There is currently an abundance of evidence on the positive effects of probiotics on human health [1-5]. Probiotics are typically bacteria of the species Lactobacillus or Bifidobacterium [6], which are natural components of the gut microbiota and are thus able to survive in the gut. Among lactic acid bacteria (LAB), members of the genus Lactobacillus are generally regarded as non-pathogenic because of their long history of safe use as health-promoting organisms in numerous fermented food products - e.g., dairy products, fermented vegetables, fish and sausages - as well as silage inoculants $[5,7,8]$. Lactobacillus rhamnosus (L. rhamnosus) has been shown to produce lactic acid as the only carbohydrate metabolism product $[9,10]$.

Lactic acid was first manufactured on a commercial scale in the United States in 1883 by lactic acid bacterial fermentation of sugar substrates [11]. Lactic acid bacteria of the genus Lactobacillus have been employed in manufacturing lactic acid. A natural organic acid with a long history of application in the food, leather, cosmetic, and pharmaceutical industries [12], lactic acid has also been described as a very effective exfoliating and moisturizing agent [13]. Its application at low concentration (5\% v/v) decreases intercorneocyte cohesion and induces skin peeling [14]. Therefore, different concentrations of lactic acid produce different cosmetic results in the epidermis and dermis [15].

In the last few years, LAB were widely distributed in foods due to their beneficial effects on health, such increasing the innate immune response [16], helping to control intestinal infections [17], influencing cholesterol levels [18], antioxidant [19], and anticarcinogenic effects [20]. Some possible mechanisms of action maybe include the production of acid and other by-products of bacterial metabolism in the spent culture supernatant (SCS). For intestinal infections, SCS of the L. rhamnosus GG had been reported to exert antibacterial activity against Salmonella typhimurium [21]. L. fermentum-secreted compounds in SCS inhibit the growth, cytotoxicity and biofilm formation of several S. aureus and P. aeruginosa strains [22]. Three human-isolated Lactobacillus strains show antagonistic activity against ETEC infection in vitro [23]. SCS of L. plantarum 2142 can protect the response of enterocytes to oxidative stress from oxidative injury [24]. Although LAB strains have been shown to have wide applications, LAB culture filtrates are usually discarded and have not been studied in detail. There are no reports on the application of L. rhamnosus culture filtrate for use in cosmetic skin care products. The objective of this study was to investigate the effectiveness of L. rhamnosus spent culture supernatant (Lr-SCS) in cosmetics, with the aim of developing a possible new green cosmetic material.

\section{Results and Discussion}

\subsection{DPPH Scavenging Activity Assay}

DPPH is a stable free radical compound that has been widely used to measure the free radicalscavenging activity and hydrogen-donating ability of antioxidants. Figure 1 shows the DPPH radical scavenging activity of Lr-SCS samples increases in a dose-dependent manner. The radical scavenging activities for $10 \%, 50 \%, 100 \%$, and heated SCS were $10.2 \pm 2.9 \%, 38.1 \pm 1.6 \%, 71.7 \pm 1.7 \%$, and $70.7 \pm 1.5 \%$, respectively. The DPPH radical-scavenging activities of BHA at 0.25 and $0.5 \mathrm{mg} / \mathrm{mL}$ were $46.4 \pm 1.9 \%$ and $76.4 \pm 1.3 \%$, respectively. Moreover, the heated sample did not lose any DPPH 
scavenging activity. Heat treatment is usually needed to test the stability of a cosmetic product. The result of heat-stable Lr-SCS confirms this strain to be useful in the development of cosmetic materials.

Figure 1. DPPH radical scavenging activities of standard samples and Lr-SCS samples.

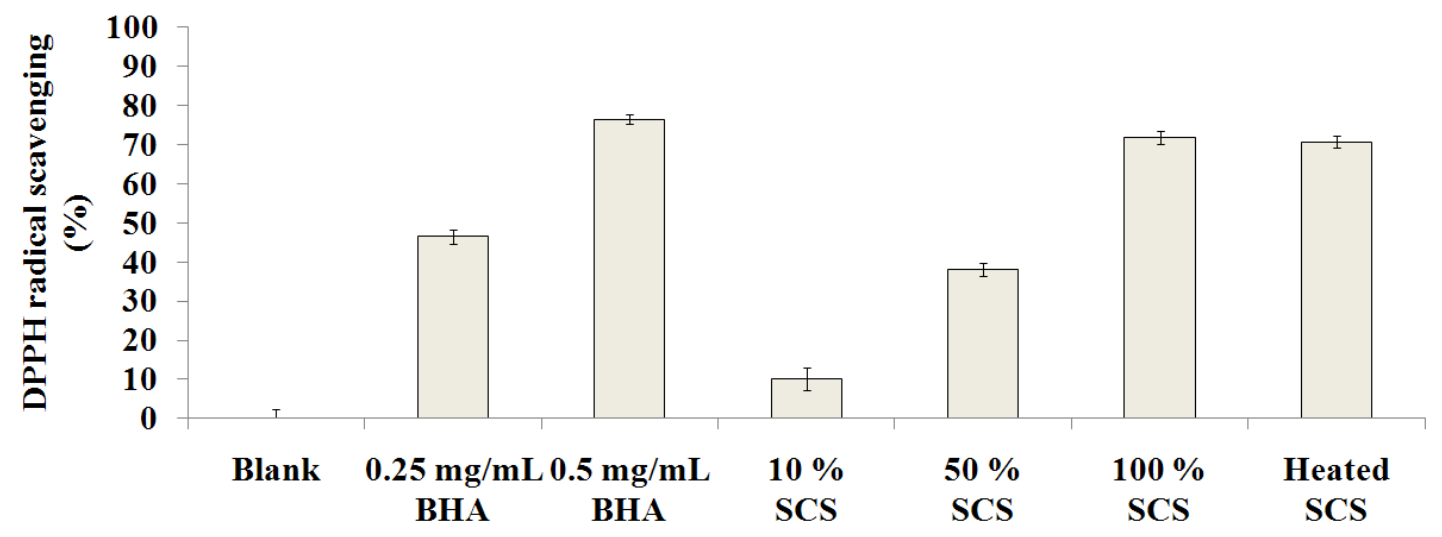

\subsection{ABTS $^{+} \cdot$ Scavenging Capacity Assay}

We compared the efficacies of Lr-SCS samples and Trolox in scavenging the $\mathrm{ABTS}^{+} \bullet$ radical. Figure 2 illustrates that $\mathrm{ABTS}^{+} \cdot$ radicals were inhibited by $26.6 \pm 1.3 \%, 54.5 \pm 1.3 \%, 82.4 \pm 0.3 \%$, and $82.8 \pm 0.9 \%$ by solutions of $10 \%, 50 \%, 100 \%$, and heated Lr-SCS, respectively. The $\mathrm{ABTS}^{+} \cdot$ radical scavenging activities of Trolox at 1 and $5 \mathrm{mM}$ were $19.7 \pm 1.9 \%$ and $78.2 \pm 1.4 \%$, respectively. Heat treatment of Lr-SCS did not influence its $\mathrm{ABTS}^{+} \cdot$ scavenging activity, which was equivalent to that of 5 mM Trolox.

Figure 2. $\mathrm{ABTS}^{+} \bullet$ radical scavenging activities of standard samples and Lr-SCS samples.

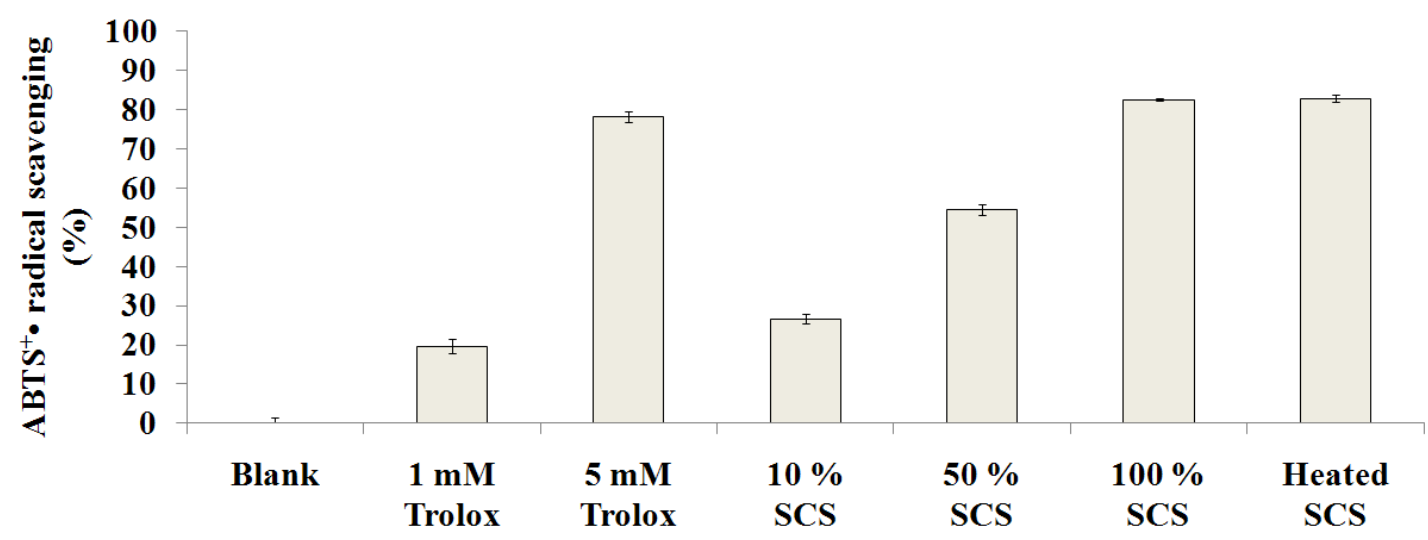

\subsection{Determination of Reducing Power}

The reducing power of Lr-SCS increased steadily with increasing concentration (Figure 3). In this study, the reducing power of samples was compared with that of $1 \mathrm{mg} / \mathrm{mL}$ BHA. The reducing powers for $10 \%, 50 \%, 100 \%$, and heated SCS were $16.2 \pm 2.7 \%, 47.4 \pm 0.8 \%, 97.6 \pm 1.6 \%$, and $97.5 \pm 1.7 \%$, respectively. Meanwhile, the reducing power of $0.25 \mathrm{mg} / \mathrm{mL}$ BHA was $31.3 \pm 1.3 \%$ and that of $0.5 \mathrm{mg} / \mathrm{mL}$ BHA was $55.8 \pm 1.9 \%$. 
Figure 3. Reducing powers of standard samples and Lr-SCS samples.

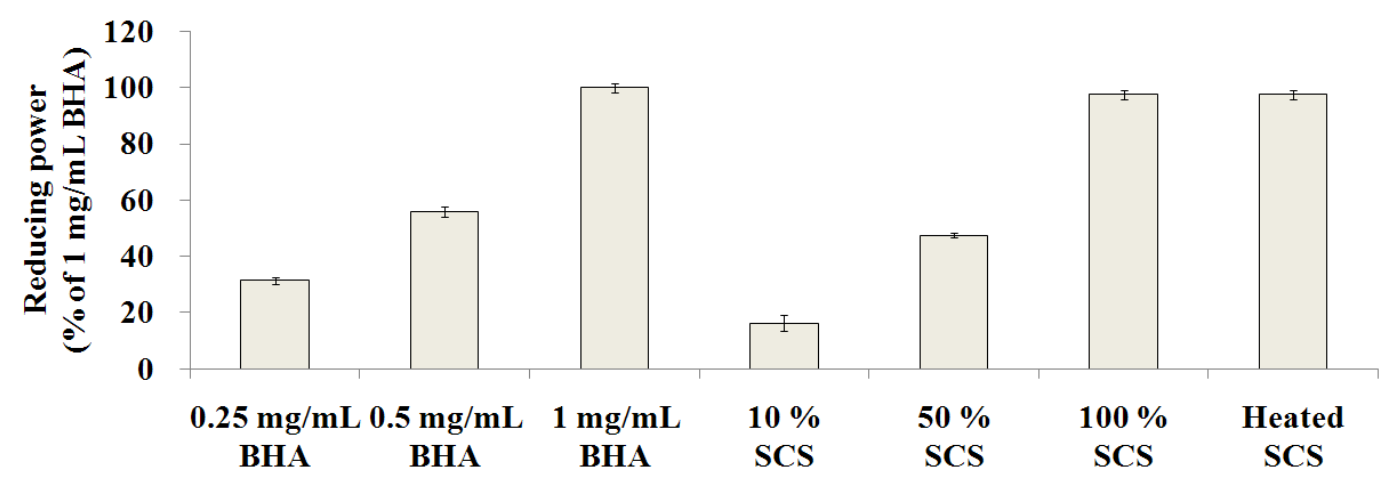

Qian et al. [25] showed that milk fermented with Lactobacillus delbrueckii ssp. bulgaricus LB340, after centrifugation and ultrafiltration, yielded peptides in the 3-5 kDa range that exhibited good antioxidant activity. Liu and Pan [26] indicated that heat-killed cells of Lactobacillus acidophilus BCRC 14079 exhibit high total antioxidant activity, which is probably related to a Maillard reaction, a reaction between sugar and amino acid in LAB culture after heating. Numerous research studies have focused on Maillard reaction products that may have some antioxidant properties, i.e., clearance of hydroxyl radicals, clearance of hydrogen peroxide, and reduction of lipid peroxidation [27-29]. Liu et al. [30] demonstrated that Lactobacillus exopolysaccharides had antioxidant properties such as DPPH radical scavenging activity, chelation of ferrous ions, and reducing power in vitro. We speculate that the source of antioxidant activity in our study may similarly result from heat-stable peptides and/or Maillard-reaction products.

\subsection{Tyrosinase Inhibitory Activity Assay}

The mushroom tyrosinase inhibitory activities for $10 \%, 50 \%, 100 \%$, and heated Lr-SCS were $20.6 \pm 0.7 \%, 47.2 \pm 1.8 \%, 71.3 \pm 2.2 \%$, and $72.1 \pm 1.2 \%$, respectively (Figure 4). Meanwhile, the mushroom tyrosinase inhibitory activities for 2 and $10 \mathrm{mM}$ kojic acid were $43.6 \pm 2.5 \%$ and $83.6 \pm 1.0 \%$, respectively. Compared with untreated Lr-SCS, heated Lr-SCS did not appear to decrease tyrosinase inhibitory activity.

Figure 4. Tyrosinase inhibitory activities of standard samples and Lr-SCS samples.

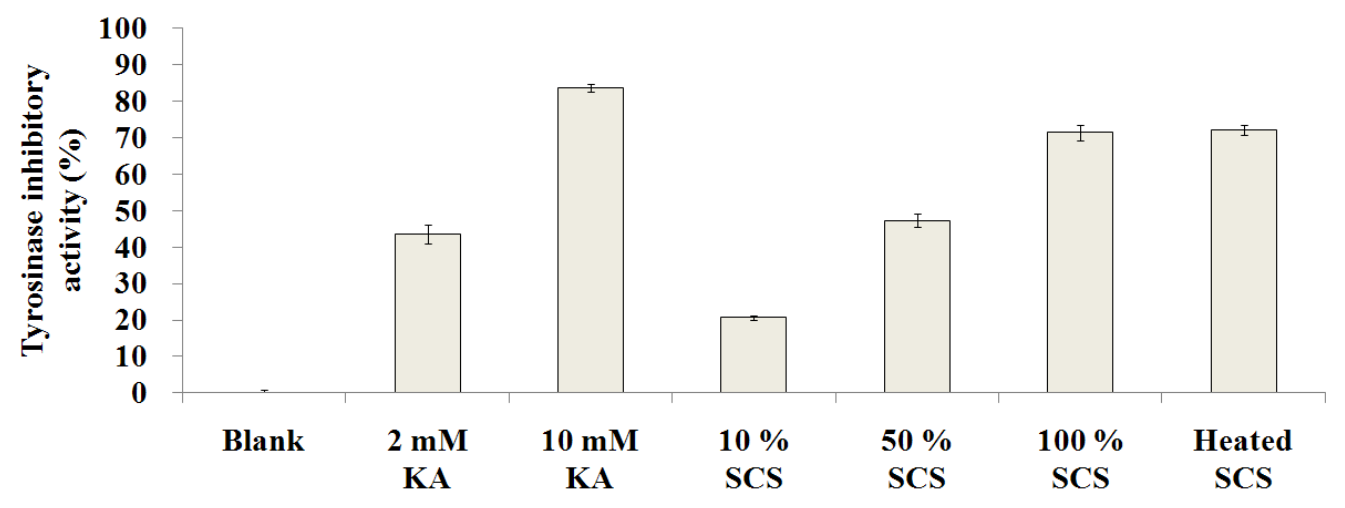


Usuki et al. [31] demonstrated that lactic acid could directly inhibit tyrosinase enzyme activity. However, this effect was not due to the acidity of lactic acid, because adjusting the $\mathrm{pH}$ did not affect inhibitory effect on tyrosinase activity. The results of this study were consistent with that report. In our study, the lactic acid in Lr-SCS, a major effective component, suppressed tyrosinase activity in vitro in a dose-dependent manner. Furthermore, heated Lr-SCS also directly inhibited tyrosinase activity.

\subsection{Evaluation of Moisture Retention}

The in vitro moisture retention property of Lr-SCS was examined gravimetrically and compared with that of glycerin, frequently used as a hygroscopic and humectant agent. Figure 5 illustrates that moisture retention activities of $10 \%, 50 \%, 100 \%$, and heated SCS were $2.2 \pm 0.1 \%, 6.5 \pm 0.4 \%$, $10.5 \pm 0.3 \%$, and $10.1 \pm 0.8 \%$, respectively. Lr-SCS showed a dose-dependent trend in moisture retention, which was not influenced by heat treatment. In addition, moisture retention by Lr-SCS was equivalent to that of $10 \%$ glycerin. Table 1 summarizes the activities of Lr-SCS from Figures 1-5.

Figure 5. Moisture retentions of standard samples and Lr-SCS samples.

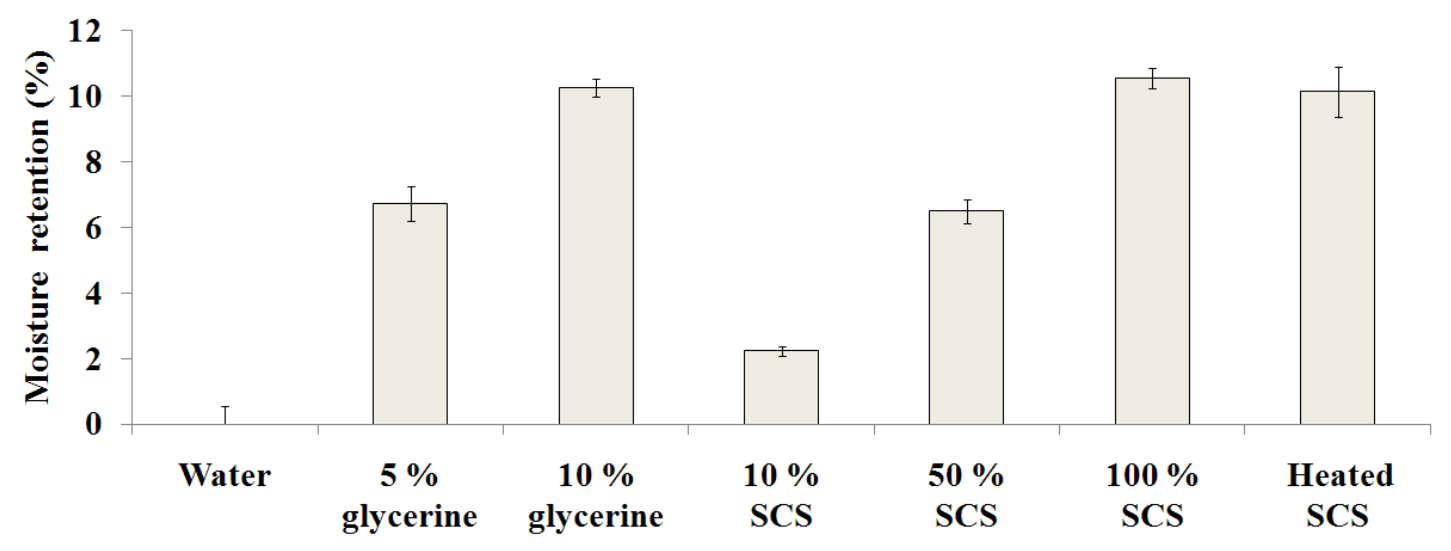

Table 1. Activities of Lactobacillus rhamnosus spent culture supernatant.

\begin{tabular}{lccccccc}
\hline \multirow{2}{*}{ Sample } & \multirow{2}{*}{ Blank } & \multicolumn{2}{c}{ Control } & \multicolumn{3}{c}{ SCS } & Heated \\
\cline { 3 - 7 } Activity & & No. 1 & No.2 & $\mathbf{1 0 \%}$ & $\mathbf{5 0 \%}$ & $\mathbf{1 0 0 \%}$ & SCS \\
\hline $\begin{array}{l}\text { DPPH } \\
\text { scavenging (\%) }\end{array}$ & $0 \pm 2.3$ & $46.4 \pm 1.8$ & $76.4 \pm 1.3$ & $10.1 \pm 2.9$ & $38.0 \pm 1.6$ & $71.7 \pm 1.7$ & $70.6 \pm 1.5$ \\
\hline $\begin{array}{l}\text { ABTS }^{+} \\
\text {scavenging (\%) }\end{array}$ & $0 \pm 1.4$ & $19.6 \pm 1.9$ & $81.5 \pm 1.6$ & $26.6 \pm 1.2$ & $54.4 \pm 1.3$ & $82.4 \pm 0.2$ & $82.8 \pm 0.8$ \\
\hline $\begin{array}{l}\text { Reducing power } \\
(\%)\end{array}$ & & $55.7 \pm 1.9$ & $100.0 \pm 1.7$ & $16.2 \pm 2.7$ & $47.4 \pm 0.8$ & $97.6 \pm 1.6$ & $97.4 \pm 1.7$ \\
\hline $\begin{array}{l}\text { Tyrosinase } \\
\text { inhibition (\%) }\end{array}$ & $0 \pm 0.7$ & $43.6 \pm 2.5$ & $83.5 \pm 1.0$ & $20.6 \pm 0.7$ & $47.1 \pm 1.8$ & $71.3 \pm 2.2$ & $72.0 \pm 1.2$ \\
\hline $\begin{array}{l}\text { Moisture } \\
\text { retention (\%) }\end{array}$ & $0 \pm 0.5$ & $6.7 \pm 0.5$ & $10.2 \pm 0.2$ & $2.2 \pm 0.1$ & $6.4 \pm 0.3$ & $10.5 \pm 0.3$ & $10.1 \pm 0.7$ \\
\hline
\end{tabular}




\subsection{Titratable Acidity and $\mathrm{pH}$ Measurement}

The titratable acidity concentration and $\mathrm{pH}$ of $10 \%, 50 \%, 100 \%$, and heated Lr-SCS were $0.16 \%$

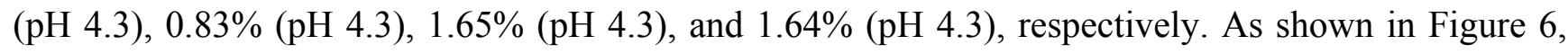
the lactic acid concentrations by the HPLC method are $0.29 \%, 0.91 \%, 1.72 \%$, and $1.68 \%$, respectively. In this study, the pH of Lr-SCS was the same across various concentrations, as well in heated Lr-SCS. The lactic acid concentration of heated Lr-SCS was the same that of $100 \% \mathrm{Lr}-\mathrm{SCS}$. It is presumed that the Lr-SCS has a good $\mathrm{pH}$ buffering capacity, probably deriving from the peptide fraction and resulting in the almost equal $\mathrm{pH}$ for different lactic acid concentrations. Lactic acid concentration was found to be correlated positively with moisture retention, in agreement with a previous report [13].

Figure 6. Intensity $v s$. retention time of lactic acid and Lr-SCS samples by HPLC.

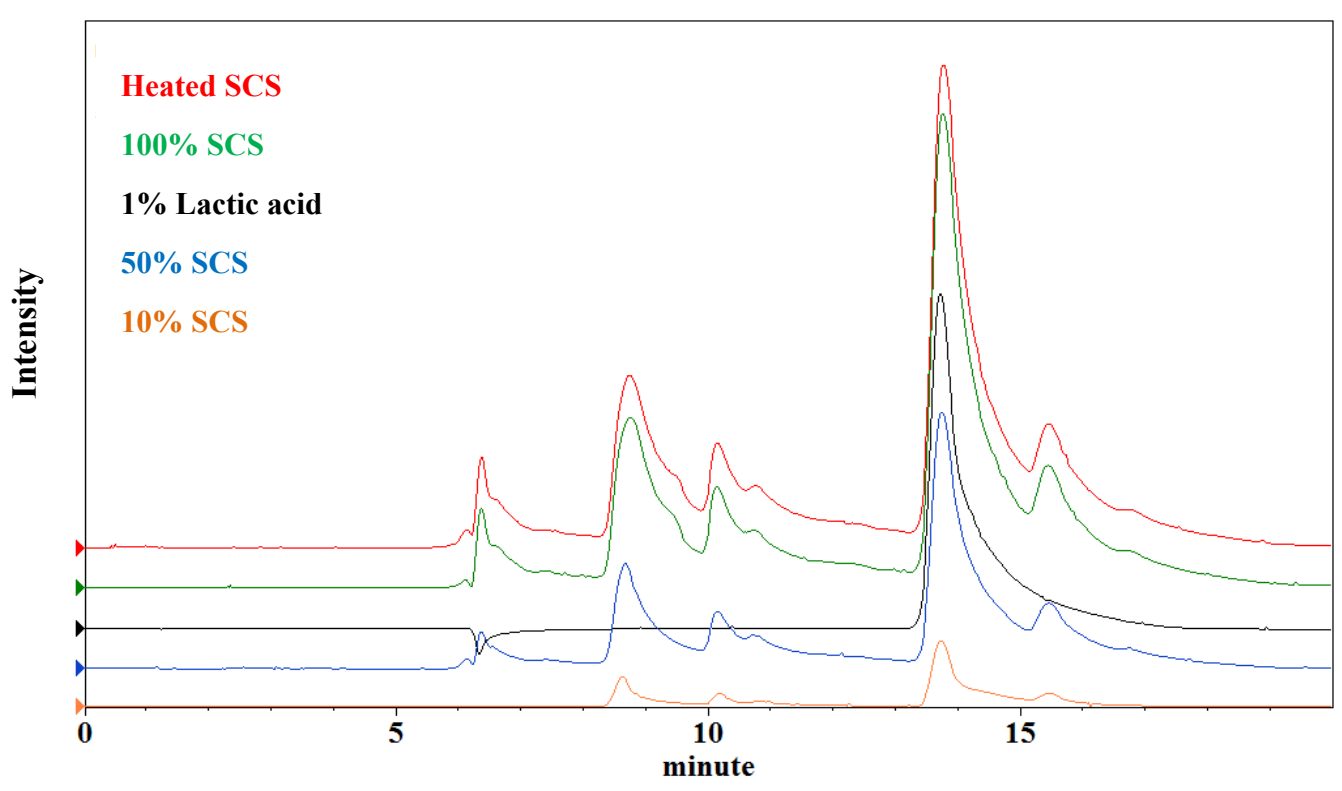

\section{Experimental}

\subsection{Materials}

The following chemicals were purchased from Sigma-Aldrich Co. (St. Louis, MO, USA): butylated hydroxyanisole (BHA); 1,1-diphenyl-2-picrylhydrazyl (DPPH); 2,2-azino-bis-(3-ethylbenzothiazoline6-sulfonic acid) (ABTS); kojic acid; L-tyrosine; and mushroom tyrosinase. Iron (III) chloride was obtained from Riedel-de Haen (Seelze, Germany), and ethanol was purchased from Merck (Darmstadt, Germany).

\subsection{Bacterial Culture}

Lactobacillus rhamnosus LRH113 was obtained from Synbiotech Biotechnology (Kaohsiung, Taiwan). The bacterial strain was inoculated at $1 \%$ in $400 \mathrm{~mL}$ de Man Rogosa Sharp (MRS) broth (Difco, Detroit, MI, USA). After anaerobic incubation for $20 \mathrm{~h}$ at $37{ }^{\circ} \mathrm{C}$ (ThermoForma, Model 1025, Marietta, OH, USA), bacterial cells were removed by centrifugation $\left(8,000 \mathrm{rpm}, 10 \mathrm{~min}, 4{ }^{\circ} \mathrm{C}\right)$, and the supernatant was passed through a $0.45-\mu \mathrm{m}$ cellulose acetate filter to obtain Lr-SCS. The samples tested 
in this study included Lr-SCS at various concentrations $(10,50,100 \mathrm{v} / \mathrm{v} \%)$ and heated $\mathrm{Lr}-\mathrm{SCS}\left(100{ }^{\circ} \mathrm{C}\right.$ for $30 \mathrm{~min}$ ).

\subsection{DPPH Scavenging Activity Assay}

The DPPH scavenging activity of samples was measured according to Zhang's method [32]. Lr-SCS $(0.1 \mathrm{~mL})$ and ethanol $(0.4 \mathrm{~mL})$ were added to DPPH $(1 \mathrm{~mL}, 0.25 \mathrm{mM})$ solution. When DPPH reacts with an antioxidant that can donate hydrogen, it is converted to a reduced form and causes a decrease in absorbance at $517 \mathrm{~nm}$ (Sunrise ELISA Plate Reader, Tecan, Salzburg, Austria). In this study, BHA (0.25 and $0.5 \mathrm{mg} / \mathrm{mL})$ was used as a standard. The percent DPPH scavenging activity was calculated using the formula: DPPH scavenging activity $(\%)=\left(1-\mathrm{A}_{\text {sample }} / \mathrm{A}_{\text {blank }}\right) \times 100$, where $\mathrm{A}$ is the absorbance at $517 \mathrm{~nm}$.

\subsection{ABTS $^{+} \cdot$ Scavenging Capacity Assay}

The $\mathrm{ABTS}^{+}$• scavenging capacity assay was carried out using the procedure described in Erkan's method [33]. In brief, $\mathrm{ABTS}^{+} \cdot$ was produced by reacting $7 \mathrm{mM}$ ABTS with $2.45 \mathrm{mM}$ potassium persulfate in the dark for 16 hours at $26{ }^{\circ} \mathrm{C}$. A $10-\mu \mathrm{L}$ Lr-SCS sample was added to $2 \mathrm{~mL} \mathrm{ABTS}^{+}$• radical solution, allowed to react for $10 \mathrm{~min}$, and the absorbance was measured at $734 \mathrm{~nm}$. The $\mathrm{ABTS}^{+} \cdot$ scavenging capacity of the sample was compared with that of Trolox (6-hydroxy-2,5,7,8tetramethylchroman-2-carboxylic acid), which is a vitamin E derivative with potent antioxidant properties and commonly used as a standard or positive control in antioxidant assays. $\mathrm{ABTS}^{+} \cdot$ scavenging activity was calculated using the formula: $\mathrm{ABTS}^{+} \cdot$ scavenging activity $(\%)=\left(1-\mathrm{A}_{\text {sample }} / \mathrm{A}_{\text {blank }}\right) \times 100$, where $\mathrm{A}$ is the absorbance at $734 \mathrm{~nm}$.

\subsection{Determination of Reducing Power}

The reducing power of each Lr-SCS sample was determined using a mixture of phosphate buffer ( $1 \mathrm{~mL}, 0.2 \mathrm{M}, \mathrm{pH} 6.6)$, potassium ferricyanide ( $1 \mathrm{~mL}, 1 \%$ by weight), and sample $(1 \mathrm{~mL})$ [34]. The mixture was then incubated for 20 minutes at $50{ }^{\circ} \mathrm{C}$. A volume of trichloroacetic acid $(1 \mathrm{~mL}, 1 \%$ by weight) was added to the mixture, which was then centrifuged at for $10 \mathrm{~min}$ at 3,000 rpm. The upper layer of solution $(0.4 \mathrm{~mL})$ was mixed with distilled water $(0.5 \mathrm{~mL})$ and $\mathrm{FeCl}_{3}(1 \mathrm{~mL}, 0.1 \%$ by weight for $10 \mathrm{~min}$, and the absorbance was measured at $700 \mathrm{~nm}$. A higher absorbance of the reaction mixture was indicative of greater reducing power. Reducing power was calculated using the formula: Reducing power $(\%)=(\mathrm{A} / \mathrm{B}) \times 100$, where $\mathrm{A}$ is the sample absorbance and $\mathrm{B}$ is the absorbance of $1 \mathrm{mg} / \mathrm{mL} \mathrm{BHA}$.

\subsection{Tyrosinase Inhibitory Activity Assay}

Tyrosinase inhibitory activity was measured using the method described by Jo [35]. An aqueous solution of mushroom tyrosinase ( $2 \mu \mathrm{L}, 2$ units) was added to a 96-well microplate, following by a mixture $(120 \mu \mathrm{L})$ containing $5 \mathrm{mM}$ L-dopa dissolved in $67 \mathrm{mM}$ phosphate buffer $(\mathrm{pH} 6.8)$ and a Lr-SCS sample $(20 \mu \mathrm{L})$. The assay mixture was incubated for 30 minutes at $37{ }^{\circ} \mathrm{C}$. Following incubation, the amount of dopachrome produced in the reaction mixture was determined by spectrophotometric analysis at $490 \mathrm{~nm}$. In this study, kojic acid (10 and $2 \mathrm{mM}$ ) was used as a standard. 
Percent inhibition of tyrosinase activity was calculated using the formula: Inhibition $(\%)=(1-$ $\left.\mathrm{OD}_{\text {sample }} / \mathrm{OD}_{\text {blank }}\right) \times 100$, where $\mathrm{OD}$ is optical density at $490 \mathrm{~nm}$.

\subsection{Evaluation of Moisture Retention}

The weight loss of a sample was used for evaluation of moisture retention. A Lr-SCS sample $(900 \mu \mathrm{L})$ was placed in a glass tube and transferred for 96 hours to an oven with constant temperature and humidity $\left(50{ }^{\circ} \mathrm{C}, 60 \%\right.$ relative humidity). The weights before $\left(\mathrm{W}_{0}\right)$ and after $\left(\mathrm{W}_{\mathrm{t}}\right)$ the incubation were recorded by an electronic balance (XS 225A, Precisa Gravimetrics AG, Dietikon, Switzerland). In this study, glycerin was used as a moisture retention standard because it is a well-known cosmetic ingredient, and it exists in the stratum corneum as a natural endogenous humectant [36]. The moisture retention rate $(\mathrm{Rr})$ was evaluated by the weight loss of the sample: $\operatorname{Rr}(\%)=\left[1-\left(\mathrm{W}_{0, \text { sample }}-\mathrm{W}_{\mathrm{t}, \text { sample }}\right) /\right.$ $\left.\left(\mathrm{W}_{0, \text { control }}-\mathrm{W}_{\mathrm{t}, \text { control }}\right)\right] \times 100$.

\subsection{Titratable Acidity and pH Measurement}

Titratable acidity was assessed by the titration method of Nwafor and Ikenebomeh [37]. A Lr-SCS sample (approximately $10 \mathrm{~g}$ ) was mixed with $0.5 \%$ (w/v ethanol) phenolphthalein solution $(0.5 \mathrm{~mL})$ and titrated by $0.1 \mathrm{~N} \mathrm{NaOH}$ until a faint pink color persisted. The $\mathrm{pH}$ was measured using a $\mathrm{pH}-\mathrm{meter}$ (SP-2300, Suntex Instruments Company Ltd, Taichung, Taiwan). Percent lactic acid was determined using the formula: $\mathrm{LA} \%=100 \times(0.1 \mathrm{~N} \mathrm{NaOH}$ required $\times 0.1 \mathrm{~N} \mathrm{NaOH}$ factor $\times 0.009) \div($ sample weight $)$. High performance liquid chromatography (HPLC) analysis on lactic acid content was performed on a Hitachi L-7100 system (Merck-Hitachi, Darmstadt, Germany) equipped with a RI detector and an organic acid column (Rezex $\mathrm{ROA} \mathrm{H}^{+}$form, $5 \mu \mathrm{m}, 300 \times 7.8 \mathrm{~mm}$ I.D.; Phenomenex, Torrance, CA, USA). The flow rate was $0.6 \mathrm{~mL} / \mathrm{min}$ with a solvent of $0.005 \mathrm{~N} \mathrm{H}_{2} \mathrm{SO}_{4}$ at $75{ }^{\circ} \mathrm{C}$.

\section{Conclusions}

This is the first report that has evaluated Lactobacillus rhamnosus spent culture supernatant for cosmetic use. We examined six assays: DPPH scavenging activity, $\mathrm{ABTS}^{+} \bullet$ scavenging capacity, reducing power, tyrosinase inhibitory activity, moisture retention, and titratable acidity. Lr-SCS showed dose-dependent increases in lactic acid concentration, antioxidant activity, inhibitory tyrosinase synthesis, and moisture retention. Heat treatment did not destroy the active components of Lr-SCS for these assays. In the future, we will further analyze the active components in Lr-SCS and elucidate the antioxidant and whitening mechanisms for skin care cosmetics.

\section{Acknowledgments}

This work was supported by a grant (NSC 102-2632-B-241-001-MY3) from the National Science Council of Taiwan, Taiwan.

\section{Conflicts of Interest}

The authors declare that they have no competing interests. 


\section{References}

1. Mattila-Sandholm, T.; Myllärinen, P.; Crittenden, R.; Mogensen, G.; Fondén, R.; Saarela, M. Technological challenges for future probiotic foods. Int. Dairy J. 2002, 12, 173-182.

2. Millette, M.; Luquet, F.M.; Ruiz, M.T.; Lacroix, M. Characterization of probiotic properties of Lactobacillus strains. Dairy Sci. Technol. 2008, 88, 695-705.

3. O’May, G.A.; MacFarlane, G.T. Health claims associated with probiotics. In Probiotic Dairy Products 2nd ed.; Tamime, A., Ed.; Blackwell Publishing Ltd: Oxford, UK, 2005; pp. 138-166.

4. Parvez, S.; Malik, K.A.; Ah Kang, S.; Kim, H.Y. Probiotics and their fermented food products are beneficial for health. J. Appl. Microbiol. 2006, 100, 1171-1185.

5. Giraffa, G.; Chanishvili, N.; Widyastuti, Y. Importance of lactobacilli in food and feed biotechnology. Res. Microbiol. 2010, 161, 480-487.

6. Klein, G.; Pack, A.; Bonaparte, C.; Reuter, G. Taxonomy and physiology of probiotic lactic acid bacteria. Int. J. Food Microbiol. 1998, 41, 103-125.

7. Arihara, K.; Ota, H., Itoh, M.; Kondo, Y.; Sameshima, T.; Yamanaka, H.; Akimoto, M.; Kanai, S.; Miki, T. Lactobacillus acidophilus group lactic acid bacteria applied to meat fermentation. J. Food Sci. 1998, 63, 544-547.

8. Hammes, W.P.; Hertel, C. New developments in meat starter cultures. Meat Sci. 1998, 49, $125-138$.

9. Petrov, K.K.; Yankov, D.S.; Beschkov, V.N. Lactic acid fermentation by cells of Lactobacillus rhamnosus immobilized in polyacrylamide gel. World J. Microb. Biot. 2006, 22, 337-345.

10. Ho, K.L.; Pometto, G.; Dickson, J.S.; Demirci, A. Ingredient selection for plastic composite supports for L-(+)-lactic acid biofilm fermentation by Lactobacillus casei subsp. rhamnosus. Appl. Environ. Microb. 1997, 63, 2516-2523.

11. Litchfield, J.H. Lactic acid microbially produced. In Encyclopedia of Microbiology 2nd ed.; Schaechter, M., Ed.; Academic Press: San Diego, CA, USA, 2009; pp. 362-372.

12. Wee, Y.J.; Kim, J.N.; Ryu, H.W. Biotechnological production of lactic acid and its recent applications. Food Technol. Biotechnol. 2006, 44, 163-172.

13. Hasegawa, S.; Azuma, M.; Takahashi, K. Stabilization of enzyme activity during the esterification of lactic acid in hydrophobic ethers and ketones as reaction media that are miscible with lactic acid despite their high hydrophobicity. Enzyme Microb. Tech. 2008, 43, 309-316.

14. Babilas, P.; Knie, U.; Abels, C. Cosmetic and dermatologic use of alpha hydroxy acids. J. Dtsch. Dermatol. Ges. 2012, 10, 488-491.

15. Rendl, M.; Mayer, C.; Weninger, W.; Tschachler, E. Topically applied lactic acid increases spontaneous secretion of vascular endothelial growth factor by human reconstructed epidermis. Br. J. Dermatol. 2001, 124, 3-9.

16. Jain, S.; Yadav, H.; Sinhá, P.R. Stimulation of innate immunity by oral administration of dahi containing probiotic Lactobacillus casei in mice. J. Med. Food. 2008, 11, 652-656.

17. Timmerman, H.M.; Koning, C.J.M.; Mulder, L.; Rombouts, F.M.; Beynen, A.C. Monostrain, multistrain and multispecies probiotics - A comparison of functionality and efficacy. Int. J. Food Microbiol. 2004, 96, 219-233. 
18. Nguyen, T.D.T.; Kang, J.H.; Lee, M.S. Characterization of Lactobacillus plantarum PH04, a potential probiotic bacterium with cholesterol-lowering effects. Int. J. Food Microbiol. 2007, $113,358-361$.

19. Liang, T.W.; Wu, Y.Y.; Huang, T.Y.; Wang, C.Y.; Yen, Y.H.; Liu, C.P.; Chen, Y.C.; Wang, S.L. Conversion of squid pen by a novel strain Lactobacillus paracasei subsp. paracasei TKU010, and its application in antimicrobial and antioxidants activity. J. Gen. Appl. Microbiol. 2010, 56, 481-489.

20. Commane, D.; Hughes, R.; Shortt, C.; Rowland, I. The potential mechanisms involved in the anti-carcinogenic action of probiotics. Mutat. Res. 2005, 591, 276-289.

21. De Keersmaecker, S.C.; Verhoeven, T.L.; Desair, J.; Marchal, K.; Vanderleyden, J.; Nagy, I. Strong antimicrobial activity of Lactobacillus rhamnosus GG against Salmonella typhimurium is due to accumulation of lactic acid. FEMS Microbiol. Lett. 2006, 259, 89-96.

22. Varma, P.; Nisha. N.; Dinesh, K.R.; Kumar, A.V.; Biswas, R. Anti-infective properties of Lactobacillus fermentum against Staphylococcus aureus and Pseudomonas aeruginosa. J. Mol. Microbiol. Biotechnol. 2011, 20, 137-143.

23. Tsai, C.C.; Lin, P.P.; Hsieh, Y.M. Three Lactobacillus strains from healthy infant stool inhibit enterotoxigenic Escherichia coli grown in vitro. Anaerobe 2008, 14, 61-67.

24. Paszti-Gere, E.; Csibrik-Nemeth, E.; Szeker, K.; Csizinszky, R.; Palocz, O.; Farkas, O.; Galfi, P. Lactobacillus plantarum 2142 prevents intestinal oxidative stress in optimized in vitro systems. Acta Physiol. Hung. 2013, 100, 89-98.

25. Qian, B.; Xing, M.; Cui, L.; Deng, Y.; Xu, Y.; Huang, M.; Zhqng, S. Antioxidant, antihypertensive, and immunomodulatory activities of peptide fractions from fermented skim milk with Lactobacillus delbrueckii ssp. bulgaricus LB340. J. Dairy Res. 2011, 78, 72-79.

26. Liu, C.F.; Pan, T.M. In vitro effects of lactic acid bacteria on cancer cell viability and antioxidant activity. J. Food Drug Anal. 2010, 18, 77-86.

27. Umetsu, H.; Ikeda, N.; Nguyen, V.C. Effects of Maillard reaction products on the oxidative cleavage and polymerization of protein under ascorbic acid-transition metal system. Biosci. Biotechnol. Biochem. 1999, 63, 1181-1186.

28. Dong, S.; Wei, B., Chen, B.; McClements, D.J.; Decker, E.A. Chemical and antioxidant properties of casein peptide and its glucose Maillard reaction products in fish oil-in-water emulsions. J. Agric. Food Chem. 2011, 59, 13311-13317.

29. Kitts, D.D.; Chen, X.M.; Jing, H. Demonstration of Antioxidant and Anti-inflammatory Bioactivities from Sugar-Amino Acid Maillard Reaction Products. J. Agric. Food Chem. 2012, 60, 6718-6727.

30. Liu, C.F.; Tseng, K.C.; Chiang, S.S.; Lee, B.H.; Hsu, W.H.; Pan, T.M. Immunomodulatory and antioxidant potential of Lactobacillus exopolysaccharides. J. Sci. Food Agric. 2011, 91, 2284-2291.

31. USuki, A.; Ohashi, A.; Sato, H.; Ochiai, Y.; Ichihashi, M.; Funasaka, Y. The inhibitory effect of glycolic acid and lactic acid on melanin synthesis in melanoma cells. Exp. Dermatol. 2003, 12, $43-50$.

32. Zhang, Y.; Wang, Z.H. Phenolic composition and antioxidant activities of two Phlomis species: A correlation study. CR Biol. 2009, 332, 816-826. 
33. Erkan, N.; Ayranci, G.; Ayranci, E. Antioxidant activities of rosemary (Rosmarinus officinalis L.) extract, blackseed (Nigella sativa L.) essential oil, carnosic acid, rosmarinic acid and sesamol. Food Chem. 2008, 110, 76-82.

34. Shyu, Y.S.; Lin, J.T.; Chang, Y.T.; Chiang, C.J.; Yang, D.J. Evaluation of antioxidant ability of ethanolic extract from dill (Anethum graveolens L.) flower. Food Chem. 2009, 115, 515-521.

35. Jo, Y.H.; Seo, G.U.; Yuk, H.Y.; Lee, S.C. Antioxidant and tyrosinaseinhibitoryactivities of methanolextracts from Magnolia denudata and Magnolia denudata var. Purpurascens flowers. Food Res. Int. 2012, 47, 197-200.

36. Verdier-Sévrain, S.; Bonté, F. Skin hydration: a review on its molecular mechanisms. J. Cosmet. Dermatol. 2007, 6, 75-82.

37. Nwafor, O.E.; Ikenebomeh, M.J. Effects of different packaging materials on 399 microbiological, physio-chemical and organoleptic quality of zobo drink storage at 400 room temperature. Afr. J. Biotechnol. 2009, 8, 2848-2852.

Sample Availability: Samples of the Lactobacillus rhamnosus LRH113 are available from the authors.

(C) 2013 by the authors; licensee MDPI, Basel, Switzerland. This article is an open access article distributed under the terms and conditions of the Creative Commons Attribution license (http://creativecommons.org/licenses/by/3.0/). 